\title{
Implementasi Network Attached Storage (NAS) Menggunakan NAS4Free untuk Media Backup File
}

\author{
Kartika Imam Santoso ${ }^{1}$, Muhamad Abdul Muin ${ }^{2}$ \\ ${ }^{1}$ Prodi Sistem Informasi, STMIK Bina Patria Magelang \\ ${ }^{2}$ Prodi Teknik Informatika, STMIK Bina Patria Magelang \\ Email: ${ }^{1}$ kartikaimams@gmail.com, ${ }^{2}$ muinmuhammad@gmail.com
}

\begin{abstract}
Abstrak
STMIK Bina Patria Magelang adalah sekolah tinggi yang berada di jalan Raden Saleh No.2 Magelang, yang membidangi dalam ilmu komputer. STMIK Bina Patria mempunyai file-file pekerjaan yang sangat penting dan privasi, sehingga perlu untuk adanya sistem yang berguna untuk backup file. Network Attached Storage (NAS) adalah sebuah server dengan sistem operasi yang dikhususkan untuk melayani kebutuhan berkas data. NAS dapat berbentuk perangkat yang siap pakai atau berupa sebuah software yang akan di-install-kan pada sebuah komputer agar berubah fungsi menjadi server NAS. Untuk software ini menggunakan NAS4Free yang berbasis linux. Model pengembangan sistem menggunakan Network Development Life Cycle (NDLC), adapun siklus tahapannya berisi analysis, design, simulation, prototyping, implementation, monitoring sehingga perencanaan yang akan dilakukan diharapkan bisa maksimal. Berdasarkan hasil pengujian terhadap rata-rata upload-nya adalah 3,5 Mbps, sedangkan untuk rata-rata download-nya adalah 5,63Mbps.
\end{abstract}

Kata Kunci: Network Attached Storage (NAS), Network Development Life Cycle (NDLC), NAS4Free.

\section{PENDAHULUAN}

Pada saat ini sistem komputer dan jaringan merupakan bagian penting dalam kehidupan manusia. Hal ini dapat dilihat dengan banyaknya penggunaan komputer saat ini pada kantor, perusahaan, pabrik-pabrik atau bahkan kampus telah mencapai jumlah yang terbilang cukup besar. Komputer tersebut biasanya digunakan oleh manusia sebagai alat bantu operasional harian atau bahkan sebagai sistem yang dapat membantu menyelesaikan masalah [1].

STMIK Bina Patria Magelang adalah sekolah tinggi yang berada di jalan Raden Saleh No. 2 Magelang, yang membidangi dalam ilmu komputer. STMIK Bina Patria mempunyai file-file pekerjaan yang sangat penting dan privasi, akan tetapi file tersebut masih disimpan ke komputer masing-masing karyawan. Sehingga file tersebut harus ada backup-annya, apabila sewaktu-waktu file tersebut dibutuhkan dan hardware penyimpanan dalam komputer karyawan rusak, maka file tersebut mempunyai backup-nya. Akan tetapi, kampus STMIK Bina Patria belum mempunyai backup file sendiri, dan masih mem-backup ke google drive serta 4shared dan lainlain. Apabila file tersebut di backup ke google drive dan 4shared maupun yang lainnya privasi file tersebut kurang aman dan tidak dapat dipertanggung jawabkan.

Akbar (2014) menganalisis perbandingan kinerja FreeNAS dan NAS4Free sebagai sistem operasi jaringan Network Attached Storage (NAS) pada Local Area Network 
(LAN). Hasil kajiannya dapat memberikan rekomendasi dan gambaran terhadap keputusan memilih sistem operasi NAS yang akan diterapkan pada jaringan Local Area Network sesuai dengan kebutuhan dengan pertimbangan performa yang ditunjukkan pada masing-masing sistem operasi jaringan. Kesimpulanya bahwa NAS4Free mempunyai berbagai keunggulan [2].

Data Loss Prevention System merupakan sebuah sistem yang akan melakukan skenario backup terhadap komputer client sehingga data penting yang ada pada komputer client menjadi aman dari terjadinya kerusakan. Sistem ini akan menggunakan aplikasi atau protokol rsync yang handal dalam melakukan proses penyalinan dan duplikasi tree atau struktur direktori secara rekursif. Tree tersebut akan di backup pada infrastruktur atau server. Proses backup tetap dapat dijalankan oleh server ketika penjadwalan pada satu rsync task disusun sama dengan rsync task lainnya. Sehingga walaupun memiliki jadwal yang sama, komputer server tetap mampu melakukan backup data dari dua NAS yang dapat membackup data secara terjadwal [1].

Santo [3] menjelaskan kegunaan pembuatan NAS (Network Attached Storage) di SMK Negeri 1 Pasuruan yang bertujuan untuk menyediakan layanan penyimpanan data pembelajaran, baik berupa e-book, jurnal elektronik, modul pembelajaran, maupun tugas-tugas individual. Dalam NAS Server terdapat bebagai fasilitas layanan sharing data yaitu FTP, CIFS/Samba, NFS. Langkah pertama dengan menginstal NAS server dengan sistem operasi FreeNAS terlebih dahulu, dilanjutkan dengan konfigurasi dasar untuk memberikan alamat IP pada NAS server. Setelah proses instalasai dan konfigurasi dasar, maka dilanjutkan dengan penambahan disk, mounting disk, mengaktifkan servis samba kemudian user management. Dengan adanya NAS server maka proses sharing data antar laboratorium dapat lebih mudah dilakukan" Dan hal ini sangat membantu dalam proses belajar mengajar di SMK Negeri 1 Pasuruan"[3].

\section{METODE}

\subsection{Teori Pendukung}

\section{1) Network Attached Storage (NAS)}

Network Attached Storage (NAS) adalah sebuah server dengan sistem operasi yang dikhususkan untuk melayani kebutuhan berkas data. NAS dapat berbentuk perangkat yang siap pakai atau berupa sebuah software yang akan di-install-kan pada sebuah komputer agar berubah fungsi menjadi server NAS. NAS dapat diakses langsung melalui jaringan area lokal dengan protokol seperti TCP/IP. File transfer protocol yang didukung oleh NAS termasuk Network File System, Common Internet File System, File Tranfer Protocol dan sebagainya [1].

Network attached storage (NAS) adalah suatu konsep penyimpanan bersama pada suatu jaringan. NAS berkomunikasi menggunakan Network File System (NFS) untuk UNIX, Common Internet File System (CIFS) untuk Microsoft Windows, FTP, http dan protokol networking lainnya. NAS membawa kebebasan platform dan meningkatkan 
kinerja bagi suatu jaringan. NAS device biasanya merupakan dedicated singlepurpose machine [4].

\section{2) Jaringan Komputer}

Jaringan komputer adalah sekelompok komputer otonom yang saling dihubungkan satu dengan lainnya menggunakan protocol komunikasi melalui media komunikasi [5]. Dengan adanya jaringan komputer maka antar komputer, dapat saling berbagi data dan informasi, aplikasi-aplikasi, Sistem Informasi dan program-program lainnya. Saling berbagi pakai perangkat keras seperti printer, hardisk, alat pemindai dan sebagainya [6].

\section{3) Server}

Secara umum, server berperan menerima pesan permintaan layanan dari client, kemudian memproses permintaan tersebut dan mengirimkan kembali hasil permintaan ke client. Sebuah komputer client yang me-request atau meminta layanan ke komputer server, akan disediakan atau dilayani oleh komputer server. Server itu ada bermacam-macam. Mulai dari Web Server, Komputer Server, Server Aplikasi.lain. Dalam kajian artikel ini server digunakan untuk melayani para client mengunduh dan mengunggah berupa file-file [5].

\section{4) Client}

Client merupakan terminal yang digunakan oleh pengguna untuk meminta layanan tertentu yang dibutuhkan. Terminal client dapat berupa PC, ponsel, komunikator, robot, televisi dan peralatan lainnya yang membutuhkan informasi [5].

\subsection{Pengembangan Sistem}

1) Metode Pengembangan Sistem

Metode yang digunakan dalam artikel ini adalah metode NDLC (Network Development Life Cycle), adapun siklus tahapannya berisi analysis, design, simulation, prototyping, implementation, monitoring dan management yang bagannya bisa dilihat pada Gambar 1 .

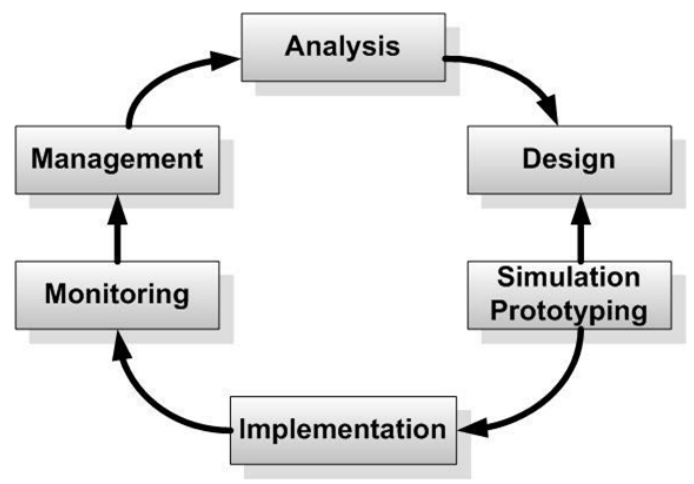

Gambar 1. Metode pengembangan NDLC [7] 
a) Analisis

STMIK Bina Patria mempunyai file-file pekerjaan yang sangat penting dan privasi, akan tetapi file tersebut masih disimpan di komputer masing-masing dosen dan karyawan. File-file tersebut memerlukan tempat untuk backup apabila sewaktu-waktu file-file tersebut dibutuhkan dan menghindari kemungkinan hardware penyimpanan dalam komputer rusak. Selama ini backup file dilakukan sendiri-sendiri, baik ke CD/DVD, HDD Eksternal dan ke google drive serta 4shared dan lain-lain. Apabila file-file tersebut di backup ke google drive dan 4shared maupun yang lainnya privasi file tersebut kurang aman dan tidak dapat dipertanggung jawabkan.

b) Perancangan (Design)

Perancangan topologi jaringan ini berdasarkan tentang konsep dan gambaran yang mendeskripsikan perangkat sebenarnya dalam suatu system yang digambarkan dengan topologi pada Gambar 2.

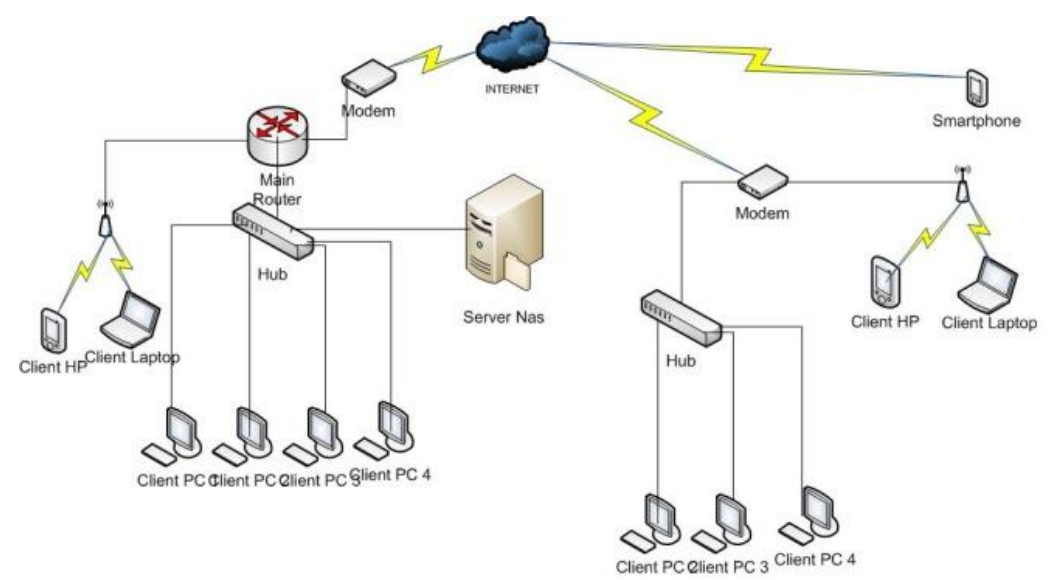

Gambar 2. Topologi jaringan dan akses NAS

c) Simulation Prototyping

Tahap selanjutnya adalah pembuatan prototype sistem yang akan dibangun, sebagai simulasi dari implementasi sistem, prototipe sistem ini pada lingkungan virtual, dengan menggunakan mesin virtual, sebagai prototype dari sistem yang akan dibuat. Software yang digunakan untuk mesin virtual adalah Virtual Mechine dan simulasinya menggunakan packet tracer.

\section{HASIL DAN PEMBAHASAN}

\subsection{Pengujian Download dan Upload pada LAN}

a) Pengujian download

Hasil pengukuran download dengan aplikasi bandwidth monitor dapat dilihat pada Gambar 3 dengan kecepatan maksimal 99.8 Mbps dan rata-rata untuk download-nya adalah 19.1 Mbps. Dengan uji coba 1 client dengan besar kapasitas file yang ditransfer adalah $82 \mathrm{Mb}$. 


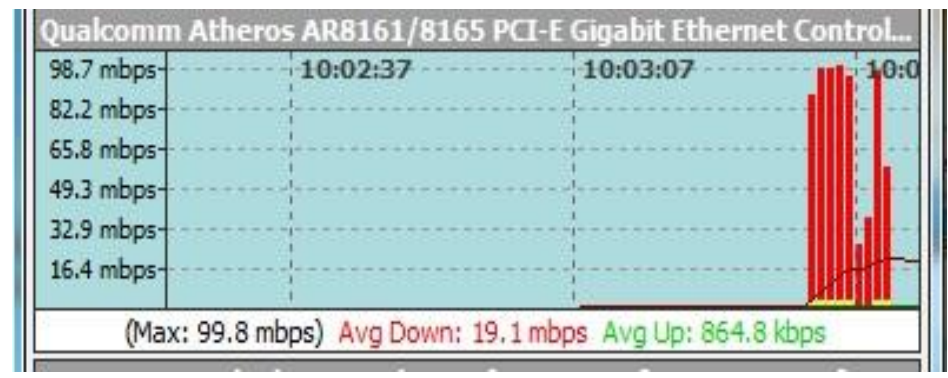

Gambar 3. Download 1 client besar file $82 \mathrm{MB}$

Sedangkan hasil pengukuran download dengan aplikasi bandwidth monitor dapat dilihat pada Gambar 4 dengan kecepatan maksimal 99.2 Mbps dan ratarata untuk download-nya adalah $6.18 \mathrm{Mbps}$. Dengan uji coba 3 client dengan besar kapasitas file yang ditransfer adalah 290Mb.

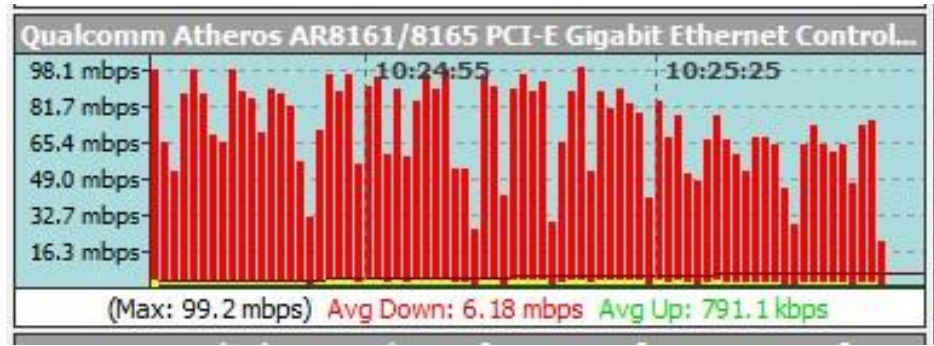

Gambar 4. Download 3 client besar file 290MB

b) Pengujian upload

Hasil pengukuran berupa upload pada aplikasi bandwidth monitor dapat dilihat pada Gambar 5. Kecepatan maksimal upload $99.7 \mathrm{Mbps}$, dan rata-rata uploadnya adalah $3.82 \mathrm{Mbps}$. Dengan uji coba 1 client dengan besar kapasitas file yang ditransfer adalah $82 \mathrm{Mb}$.

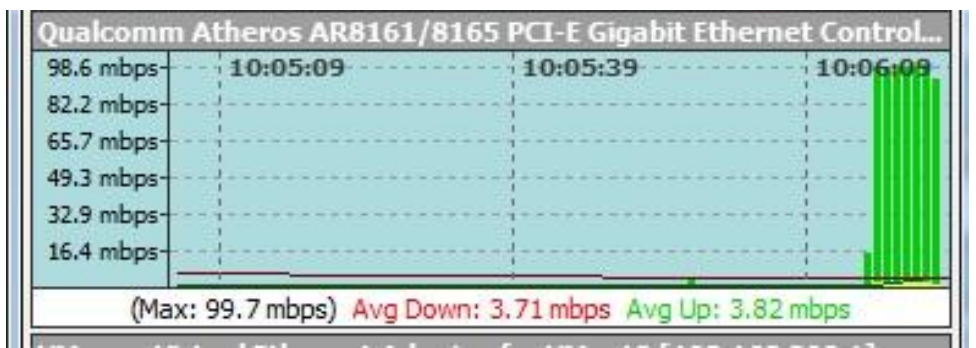

Gambar 5. Kecepatan upload 1 client

Sedangkan hasil pengukuran berupa upload dengan aplikasi bandwidth monitor pada Gambar 6 adalah kecepatan maksimal upload $99.6 \mathrm{Mbps}$ dan rata-rata upload-nya adalah $5.57 \mathrm{Mbps}$. Dengan uji coba 3 client dengan besar kapasitas file yang ditransfer adalah $290 \mathrm{Mb}$. 


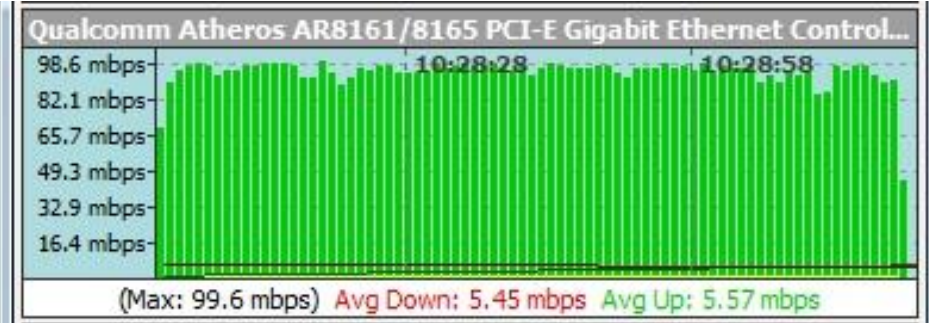

Gambar 6. Kecepatan upload 3 client

\section{SIMPULAN}

Telah dirancang dan diimplementasikan Network Attached Storage dengan menggunakan Operating system (OS) NAS4Free yang telah digunakan oleh dosen dan karyawan STMIK Bina Patria Magelang, dimana masing masing pengguna diberikan account sehingga tidak dapat diakses oleh pengguna lain dan lebih privasi. Berdasarkan hasil pengujian terhadap rata-rata upload-nya adalah $3.82 \mathrm{Mbps}$ sedangkan rata-rata untuk download-nya adalah 19.1 Mbps Dengan uji coba 1 client dengan besar kapasitas file yang ditransfer adalah $82 \mathrm{Mb}$. Untuk pengujian dengan 3 client dengan besar kapasitas file yang ditransfer adalah $290 \mathrm{Mb}$, rata-rata upload-nya adalah $5.57 \mathrm{Mb}$, sedangkan rata-rata untuk download-nya adalah 6.18 Mbps.

\section{REFERENSI}

[1] Defni, dan Prabowo, C. 2013. Perancangan dan Implementasi Data Loss Prevention System dengan menggunakan Network Attached Storage. Jurnal TEKNOIF. 1(2): 45-60.

[2] Akbar, T., dan Jusak, TS. 2014. Analisis Perbandingan Kinerja Freenas Dan NAS4Free Sebagai Sistem Operasi Jaringan Network Attached Storage (NAS) Pada Local Area Network (LAN). JSIKA. 3(1): 10-18.

[3] Santo, N. 2009. Pembuatan NAS (Network Attached Storage) server berbasis Freenas di SMK Negeri 1 Pasuruan. (Online), (http://library.um.ac.id/freecontents/downloadpubpdf.php/pembuatan-nas-network-attached-storage-serverberbasis-freenas-di-smk-negeri-1-pasuruan-nur-aini-38541.pdf, diakses 23 Maret 2015).

[4] Rendra G. 2006. Remote Virtual the Data Storage. Jurnal Informatika. 7(2): 120 -125 .

[5] Dharma, O. dan Sutejo, B. 2003. Konsep dan Perancangan Jaringan Komputer. Andi Offset, Yogyakarta.

[6] Budi, SDO., Eddy, H., Wibowo, E., Prakoso, S. 2006. Konsep dan Aplikasi Pemrograman Client Server dan Sistem Distribusi. Andi Offset, Yogyakarta.

[7] Goldman, J., A. 2001. Applied Data Communications- A Business Oriented Approach 2nd ed. John Wiley \& Sons, Inc., New York. 